\title{
LENGUAJE INCLUSIVO Y NO SEXISTA EN EL AMBITO MUSEÍSTICO DE HABLA HISPANA
}

\author{
INCLUSIVE AND NON-SEXIST LANGUAGE \\ IN SPANISH-SPEAKING MUSEUMS
}

\section{LAURA LUQUE RODRIGO*}

Resumen: El lenguaje no solo es la base de nuestra comunicación, sino también de nuestros pensamientos, es por ello que en el ámbito académico, es preciso integrar un uso del lenguaje no sexista, con el fin de educar, de forma casi inconsciente y colectiva, en igualdad. En este sentido, los museos, que aún tienen pendiente lograr una integración real en cuanto a sus contenidos, también deben cuidar el lenguaje con el que difunden sus colecciones, actividades y otras comunicaciones. En este artículo, se revisará el uso del lenguaje no sexista en el ámbito museístico de habla hispana, tomando como ejemplos algunos de los museos más relevantes de distintos países, a través de la revisión de sus medios de comunicación (páginas web, redes sociales, materiales educativos, etc.) y se expondrán los resultados de una encuesta realizada a los mismos para conocer su opinión ante esta cuestión. Además, se propondrán algunas recomendaciones en este sentido.

Palabras Clave: Lenguaje inclusivo, museos, hispano, arte, género.

ABstRACT: Language is not only the basis of our communication, but also our thoughts. That is why, in the academic world, it is necessary to incorporate the use of non-sexist language, in order, almost unconsciously and collectively, to educate in equality. In this sense, museums, which have yet to achieve real integration in terms of their contents, must also be concerned about the language with which they promote their collections, activities, etc. In this text, the use of non-sexist language in the Spanish-speaking museum field will be reviewed, taking as examples some of the most prominent museums in different countries. To do this, a review of their media (web page, social networks, educational materials, etc.) will be made and the results of a survey made to these museums will be presented to know their opinion on this issue. In addition, some recommendations in this regard will be proposed.

KEYWORDs: Inclusive language, museums, Hispanic, art, gender.

Recibido: 25.09.2019. Aceptado: 28.07.2020.

* Doctora en Historia del Arte. Académica de la Universidad de Jaén, Jaén, España. Correo electrónico: 1luque@ujaen.es. Orcid: https://orcid.org/0000-0003-2651-6948 


\section{LA INCLUSIÓN EN LOS MUSEOS}

Ci atendemos a la definición de "inclusión" de la RAE, esta nos remite a "incluir", que se define como "poner algo o a alguien dentro de una cosa o de un conjunto, o dentro de sus límites" (Diccionario RAE). Es decir, cuando mencionamos la inclusión en los museos, nos referimos a introducir en un conjunto algo o a alguien que se ha quedado fuera. En este sentido, podríamos preguntarnos, qué o quiénes forman ese conjunto, qué o quiénes se han quedado fuera y por qué. Es un hecho que la historia, tradicionalmente, tanto en nuestros museos como en nuestros manuales y libros de texto, se ha contado desde un punto de vista occidental y androcéntrico, obviando a las mujeres y la diversidad racial. Debemos tener en consideración que actualmente se considera que sin lugar a dudas el museo es un medio de comunicación y como tal, debe cuidar tanto el contenido como la forma de expresarlo: "los museos, son centros emisores de mensajes intencionados expresados a través de sus exposiciones, folletos, posters y de todos los actos y actividades que en ellos se realizan. Hoy en día, nadie duda al considerar al museo como un medio de comunicación" (GarcíaSampedro y Gutiérrez, 2018, p. 120). García Sampedro (2018) asegura que "el museo se ha distinguido por ser conformador de formas selectivas de pensamiento y memoria" (p. 51), por lo tanto, no solo educa y comunica, sino que es generador de identidad.

Es cierto que cuando hablamos de patrimonio "partimos de una situación terminológica condicionante, ya que el propio término patrimonio es una palabra masculina" (Fernández Paradas, 2017, p. 119), que hace referencia a la herencia que se recibe por línea paterna; mientras que matrimonio, su equivalente femenino, hace referencia a una unión que ha tenido tradicionalmente como fin la reproducción, entre otras cuestiones. Por lo tanto, el vocabulario elegido para hacer referencia al legado histórico-artístico, tiene ya un sesgo masculino de raíz.

Por consiguiente, si entendemos el museo como medio de comunicación y partimos de un problema etimológico de base en cuanto a la inclusión de toda la población en los discursos, la tarea se hace ardua. En este sentido, el plan Museos+ Sociales, impulsado por el Ministerio de Educación, Cultura y Deporte de España, conformado por los Museos de la Dirección General de Bellas Artes y Bienes Culturales, y de Archivos y Bibliotecas, y los dependientes de la Secretaría de Estado de Cultura de España, entre otros, se plantea que los museos sean: más abiertos, más accesibles, interculturales, inclusivos y sostenibles (Web del Ministerio de Cultura y Deporte). 
Hay que tener en cuenta que en el apartado denominado inclusivo se incorporan en un mismo grupo a mujeres y hombres, pero también a personas sin empleo, con problemas de drogadicción, enfermedades mentales, etc. Es por tanto un conjunto absolutamente heterogéneo, casi un "cajón desastre", en el que difícilmente se podrán implementar planes adecuados a cada sector mencionado. En general, y al margen de este plan, si atendemos al trabajo realizado desde los museos, podemos entender la inclusión al menos desde cuatro puntos de vista:

i) Inclusión referida a personas con discapacidades

Uno de los retos asumidos por los museos es sin duda su necesidad de hacerse accesibles para todas las personas. En este sentido, los museos han implementado mejoras en su arquitectura eliminando barreras que impedían el paso a sus espacios, las audioguías, en menor medida el braille o visitas guiadas específicas. La revista Icom Ce Digital dedicó su segundo número a este tema, Lavado (2011) afirmaba entonces que "muy pocos museos españoles pasarían un control de accesibilidad y mucho menos de un examen acerca de sus contenidos de inclusión, género o multiculturalidad" (p. 9). Algunos museos europeos y americanos (tanto del norte como del sur) han conseguido una integración mucho mayor, a través de recorridos táctiles, audiodescripciones, y espacios adecuados a la altura y cuentan con personal preparado para la atención a personas con necesidades especiales. Es esta, por lo tanto, una línea que los museos tienen en cuenta, aunque queda trabajo por hacer.

ii) Inclusión referida a la multiculturalidad

"A pesar de décadas de activismo y teorización postcolonial, feminista, antirracista y queer, el mundo del arte continúa excluyendo a los Otros Artistas: mujeres, artistas no blancos y artistas LGBTQ" (Reilly, 2017, s.p., trad. propia), por ello, la gestora cultural Reilly, propone el activismo curatorial y recoge en sus publicaciones los nombres e hitos de este activismo, que aún tiene mucho que decir. Recurre para ello a las estadísticas que hacen referencia a la presencia de mujeres y artistas no-blancos y LGTBI+ en las exposiciones de arte actual y ferias de arte.

Hernández Hernández (2010) señala que

los museos están llamados a valorar y favorecer la diversidad cultural como un elemento esencial para la sociedad en la que se han de tener 
en cuenta valores tan importantes como el diálogo y la aceptación de los demás basados en el pluralismo, la diferencia, la competencia y la creatividad. (p. 410)

En este sentido, Hernández Hernández apunta a que la multiculturalidad en el museo debe entenderse desde todas sus dimensiones, entre las que incluye, como no, la lingüística.

Si tenemos en cuenta que "la educación multicultural promueve el cambio social hacia la inclusión, el antirracismo y la equidad" (García-Sampedro y Gutiérrez, 2018, p. 122) y que una de las funciones primordiales de los museos es educar, convendremos en que es fundamental incluir a quienes han sido excluidos de la historia. Esta cuestión ha llegado incluso a tratarse por medio de la cultura pop, por ejemplo, la cantante Beyoncé junto con el rapero Jay-Z, en el videoclip de su tema Apeshit (2018), rodado en las salas del Museo del Louvre (París), plantea la ausencia de personas negras en los grandes templos de la cultura occidental. Si bien es cierto que es difícil llegar a una equidad real en este tipo de espacios, puesto que quienes encargaban las obras eran quienes ejercían el poder, es decir, hombres, blancos y ricos, los museos pueden generar discursos, incluso a partir de las ausencias, que permitan reflexionar sobre otros aspectos.

Fernández Valencia (2012) indica que "los museos son memoria de los pueblos" (p. 11), debemos, por lo tanto, enfocar la mirada correctamente, reflexionar sobre qué piezas ha ido seleccionando la historia, quiénes encargaban sus retratos, pensar a través de las obras expuestas, para descifrar los discursos históricos, y sin duda, estas nuevas narrativas deben ir acompañadas de un nuevo lenguaje.

iii) Inclusión referida al colectivo LGTBI+

Este se trata de un campo que casi no se ha empezado a estudiar, aunque sí existe un debate abierto. Fernández Paradas (2017) define

el patrimonio LGTB como un conjunto de testimonios materiales e inmateriales que evidencian la participación e importancia de los homosexuales, lesbianas, hermafroditas, travestis, etc., en las sociedades históricas, amén de manifestar, igualmente, los procesos de discriminación que estos han sufrido a lo largo de los tiempos. (p. 130)

Es evidente que existen pocos discursos museográficos al respecto, si bien hay algunas iniciativas, como el Schwules Museum de Berlín, que desde 2004 se dedica a exponer la historia del colectivo. 
iv) Inclusión referida a las mujeres

Este será el punto a desarrollar en este trabajo, sin olvidar que los dos anteriores son también importantes e incluso indisolubles, pues el feminismo actual tiene sentido desde la pluralidad y la diversidad, y no debemos olvidar la interseccionalidad ${ }^{1}$. No pretendemos incorporar a los museos a un solo tipo de mujer, sino al conjunto de las mujeres. Hay que tener presente que "la escuela fabrica, forma, construye ciudadanos y ciudadanas (...) En lo referente al género, se asume el modelo que la escuela reproduce" (Acevedo Huerta, 2010, p. 3).

Si la escuela perpetúa el modelo, la sociedad difícilmente avanzará hacia la inclusión. Pero para que la escuela avance, son necesarios materiales educativos revisados, pues "los libros de texto constituyen un pilar básico en la formación de los estudiantes, siendo mayoría los profesores que los utilizan como herramienta fundamental en el proceso enseñanza/aprendizaje de sus discípulos" (Llorent Bedmar y Cobano Delgado, 2014). Como exponen Moral Ruiz y Mantas Fernández (2019), si los libros de texto no son coeducativos en sus contenidos, tanto en los textos como en las imágenes, la educación no lo será.

[E]n este mundo en transformación, sin embargo, los sistemas educativos (...) se transforman así en agentes intencionales de discontinuidad cultural, un tipo de discontinuidad que ni refuerza los valores tradicionales ni recluta a los jóvenes para que formen parte del sistema existente. Las nuevas escuelas, con sus currícula y los conceptos que se hallan detrás de ellos, se orientan hacia el futuro. (Spindler, 1993, p. 234)

Es decir, desde hace décadas se entiende que los modelos educativos, y por tanto sus materiales, no deben inclinarse hacia la perpetuación de los roles tradicionales, sino que deben educar a las nuevas generaciones para un futuro que aún desconocemos y que podemos tratar de dibujar. En este sentido, si pretendemos un futuro donde la igualdad sea real, no solo entre sexos, sino con multiplicidad de géneros, etnias, etc., debemos trabajar en discursos, especialmente en el campo de las humanidades, que se inclinen hacia este posicionamiento. ¿Qué papel juegan, por lo tanto, los museos?

El museo, según la definición (ahora en revisión), del ICOM

\footnotetext{
${ }^{1}$ Cada individuo sufre opresión u obtiene privilegios, según su pertenencia a múltiples sectores, es decir, no es lo mismo ser un hombre que una mujer, pero tampoco es lo mismo ser una mujer blanca que negra, o ser negra pobre o rica, etc. Para más información, ver Carmen Expósito Molina (2012).
} 
es una institución (...) al servicio de la sociedad y de su desarrollo, abierta al público, que adquiere, conserva, investiga, comunica y expone el patrimonio material e inmaterial de la humanidad y su medio ambiente con fines de educación, estudio y recreo. (Web ICOM)

Podemos extraer dos cuestiones relevantes para el tema que nos ocupa. Por un lado, el primero de sus fines es el educativo, por lo tanto, sin duda los contenidos y la forma de comunicarlos no puede ser inocente, sino que juega un papel fundamental en la transmisión de valores y en la perpetuación, o no, de los roles tradicionales. Por otro lado, el Museo se yergue como un espacio para el desarrollo de la sociedad, esto es, que debe ser un motor, un revulsivo que empuje a las comunidades hacia el futuro que queramos formar, y como indica Bejarano Franco (2013), el uso del lenguaje no sexista es una herramienta para alcanzar la igualdad.

Ya "en 1989, las Guerrilla Girls nos advertían que en la sección dedicada al arte moderno del Metropolitan Museum solamente el 5\% eran mujeres, a pesar de que el 85\% eran desnudos femeninos" (García Sampedro, 2018, p. 44), ¿qué ha sucedido desde entonces? Hasta 2016 el Museo del Prado no dedicó una exposición monográfica a una mujer, pues ese año lo hizo en concreto con Clara Peeters. Esta ausencia es palpable en la mayoría de nuestros museos, como demuestran los informes de MAV (Mujeres en las Artes Visuales) y generalmente solo se palia a través de actividades relacionadas con la celebración del Día de la Mujer, 8 de marzo (Quirosa García y Amaro Martos, 2019).

\subsection{Las mujeres en los museos}

"Si pensamos que a través de la palabra el yo se construye como sujeto, el no ser llamado, el no ser nombrado por los otros en la comunicación académica obstaculiza la construcción de la subjetividad y con ello de la propia identidad" (Rubio, 2016, p. 7). Si reflexionamos sobre estas palabras de Rubio, entenderemos la importancia de emplear un vocabulario que incluya a las mujeres, pues el uso del masculino genérico, unido a la falta de mujeres en los contenidos, no hace sino contribuir a la construcción de una sociedad donde las propias mujeres se encuentran faltas de referentes que les permitan constituir su propio ser.

Esta no es una cuestión nueva, ya en 1987 la UNESCO recomendó evitar el empleo de términos que se refieren a un solo sexo, para lo que en 1999 editó sus Recomendaciones para un uso no sexista del lenguaje (Breda, 1999). Como dice Mayayo (2011), incluir el nombre de las mujeres en la 
historia del arte no es suficiente, la recuperación histórica debe acompañarse de una desarticulación de los discursos, de las bases teóricas y metodológicas (p. 51), y a esto debe añadirse el lenguaje. Debemos preguntarnos si las mujeres se reconocen en los museos.

Al referirnos a la presencia de las mujeres en los museos, se distinguen hasta cuatro grupos distintos:

i) Mujeres artistas en los museos. Son pocas las mujeres artistas con presencia en los museos, pero aún más preocupante es la escasez de mujeres artistas en las ferias de arte actuales, como ARCO, ART Madrid, JustMad o Hybrid, a las que se refiere el informe del 11 de abril de 2018 de MAV (Informe MAV). Ante esto, existen iniciativas dentro del propio colectivo artístico, por ejemplo, la artista Yolanda Domínguez realizó en ese mismo año, 2018, la acción Estamos aquí, con la colaboración de María Gimeno, que consistía en que "las artistas se pasearon por la feria luciendo una diadema con un gran signo de geolocalización rojo sobre sus cabezas, como los que usa la aplicación Google Maps" (Web Yolanda Domínguez), como forma de llamar la atención sobre la presencia de artistas mujeres.

Otra acción artística interesante, en este sentido, es la llevada a cabo por Mar García Ranedo, El señuelo (2014), donde plantea cómo "los museos son las mediaciones encargadas de enmarcar, de visibilizar, en definitiva, de dar carácter oficial e institucional a los modelos de construcción del imaginario visual y de producción de significado que se dan en el contexto cultural" (Web Mar García), y cómo ese repertorio es incompleto al no estar presentes las mujeres. Para ello, lleva un mechón de su cabello a cuatro museos y realiza un paseo por otros cuatro, mostrando en una pieza de vídeo, algunas discriminaciones patentes en el Guggenheim de Nueva York, el MoMA, el New Museum y el Whitney, todos ellos en la citada ciudad.

Estas dos acciones, y las de otras mujeres, ponen de manifiesto la incomodidad de las artistas ante la ausencia de referentes femeninos en los museos contemporáneos y en las ferias de arte actual, o en los libros de texto, como la acción de Verónica Ruth Frías consistente en escalar una pila de manuales de historia del arte donde las mujeres no aparecen (Web Verónica Ruth). No obstante, debe señalarse que en Washington existe desde 1987 un museo dedicado solo a mujeres artistas ${ }^{2}$, entre otros museos dedicados a las mujeres.

\footnotetext{
${ }^{2}$ El Museo Nacional de Mujeres Artistas nació en 1987, fue fundado por Wilhelmina Cole y está dirigido por Susan Fisher Sterling. https://nmwa.org/
} 
ii) Mujeres representadas en los museos. Las mujeres son representas en los museos en la mayoría de las ocasiones como musas, diosas de la Antigüedad, o como santas y personajes bíblicos, o por ser mujeres de personajes importantes, como madres y esposas, como la femme fatal, etc. (Mantas Fernández y Luque Rodrigo, 2010). Ciertamente, no podemos cambiar la historia y quiénes y cómo se representaban, pero sí es importante cómo la contamos y, en este sentido, algunos museos, como el Museo Nacional Centro de Arte Reina Sofía, han incorporado itinerarios de género en sus museos (Web Reina Sofía), no obstante, en demasiadas ocasiones estos discursos se limitan a eventos puntuales, generalmente relacionados con el Día de la Mujer ${ }^{3}$. Los itinerarios de los grandes museos nacionales españoles se agrupan bajo el proyecto Museos en Femenino, son cinco y llevan una guía aparejada (Web Museos en Femenino).

iii) Mujeres trabajadoras en los museos. En cuanto a las mujeres como trabajadoras en los museos, en 2016 El País se hacía eco de cómo a pesar de la abundancia de mujeres restauradoras, conservadoras y educadoras presentes en los museos (que llegan por oposiciones o concursos públicos), los cargos de máxima responsabilidad, especialmente en los grandes museos españoles (que son puestos de confianza), son ocupados por hombres (García, 2016). Esta realidad no se limita a nuestras fronteras y es común en toda Europa. En los museos españoles, en 2016, el 53,4\% de su personal eran mujeres, sin embargo, el 62,5\% de las personas que ocupaban la dirección eran hombres. Entre el personal técnico y administrativo es donde las mujeres superan con creces a los hombres, 61,5 y $61,9 \%$ de mujeres frente al 38,5 y $38,1 \%$ de hombres, en los citados puestos. Son mayoría los hombres entre el personal de limpieza y vigilancia (Estadística de museos y colecciones museográficas, 2016). Es decir, las mujeres están desempeñando labores en los museos que requieren una alta cualificación académica, $y$, sin embargo, no llegan a los puestos directivos en la misma proporción.

iv) Mujeres visitantes de los museos. Por último, en lo referente a las mujeres que visitan museos, en España la asistencia es prácticamente idéntica en ambos sexos, en concreto, para el periodo 2016 (último publicado por el MEC), el 32,3\% del total de visitantes fueron hombres frente al 34,2\% de

\footnotetext{
${ }^{3}$ En este sentido, se recomienda la explicación realizada sobre la obra La Mujer Barbuda, de Ribera (1631), por la artista Marina Núñez, donde se usa la obra para ahondar en aspectos referidos a las mujeres y al género como construcción social. Disponible en: https://www.youtube.com/watch?v=wtsW7A-yME (Consultado el 25 de junio de 2019).
} 
mujeres (Estadística de museos y colecciones museográficas, 2016, p. 10), un dato significativo, en tanto en cuanto hombres y mujeres visitan por igual nuestros museos, por lo que deben poder reconocerse igualmente en ellos.

\section{LENGUAJE INCLUSIVO Y MUSEOS}

No obstante, ya se ha tratado la importancia del uso del lenguaje inclusivo y no sexista en los puntos anteriores, debe señalarse que el artículo 14.11 de la Ley Orgánica 3/2007, de 22 de marzo, para la igualdad efectiva de mujeres $y$ hombres (España), dice que uno de los criterios generales de actuación es: "la implantación de un lenguaje no sexista en el ámbito administrativo y su fomento en la totalidad de las relaciones sociales, culturales y artísticas" (LOIEMH). Pero, ¿qué es un lenguaje inclusivo o no sexista? El uso de un lenguaje que no emplee continuamente el masculino genérico, tiene el fin de, en primer lugar, evitar textos ambiguos y confusos. Usar el femenino cuando sea preciso, sirve para visibilizar que existen mujeres realizando desempeños profesionales concretos. Esta visibilización tiene, entre otras cosas, una gran importancia para la normalización y educación, pues persigue disolver los roles de género tradicionales, y encaminarse hacia una sociedad futura más equitativa. Además, proporciona referentes a las nuevas generaciones.

Estas afirmaciones no son nuevas, ya en 1973, al inicio de la segunda ola feminista, Robin Lakoff (ver 1973) publicó el artículo Language and Woman's Place donde planteaba una reflexión en torno a la relación de hombres y mujeres con el lenguaje. Años después, los estudios de Judith Butler (El género en disputa, 1990) hicieron entender que el lenguaje contribuye a construir el género.

No obstante, también son muchas las voces críticas con respecto al uso del lenguaje inclusivo, por ejemplo, son conocidas algunas opiniones de miembros de la Real Academia de la Lengua Española, que en su Informe sobre el lenguaje inclusivo, explica como parte de su posicionamiento, que el lenguaje no es sexista, sino su uso. La RAE hace referencia en este Informe al Comité para la igualdad entre mujeres y hombres del Consejo de Europa y cómo desde 1986 se ha tendido a intentar evitar el lenguaje sexista desde las instituciones. Si bien es cierto que la Academia se posiciona a favor del masculino genérico, también ofrece en el citado Informe algunas fórmulas válidas. Asimismo, ha aceptado algunas guías de uso de lenguaje no sexista.

Para el estudio del uso del lenguaje no sexista, existen numerosos tex- 
tos que parten de los años setenta del siglo XX en el ámbito español. En este sentido, se recomienda el estudio realizado por Susana Guerrero Salazar (2012a), que analiza trece guías universitarias, publicadas entre 2008 y 2012. Sin duda, a pesar del posicionamiento a veces incluso ambiguo de la Academia, queda claro que las legislaciones vigentes y las instituciones se muestran proclives a implantar un uso no sexista del lenguaje. Es cierto que el lenguaje se transforma con el uso social, pero siendo el museo una institución generadora de identidad, comunicativa y educativa, parece evidente que su posicionamiento es clave en la construcción de la sociedad del presente y el futuro.

Es, por lo tanto, fundamental, que el museo, como lugar que educa y comunica, emplee en sus materiales y medios de información un lenguaje no sexista, que permita visibilizar a las mujeres dentro del propio museo e incluir a las mujeres que lo visitan, tanto con sus discursos y contenidos, como, por supuesto, con la forma de comunicar. De alguna manera, algunos museos ya se han percatado de esta necesidad. Por ejemplo, en 2018, el Museo de la Naturaleza y el Hombre de Tenerife, hizo un llamamiento público para buscar una nueva denominación, más inclusiva para su museo (EFE, 2018), que finalmente quedó con el nombre de Museo de Naturaleza y Arqueología (Web del Museo). Esta iniciativa no solo tiene interés por el cambio de nombre en sí, sino que por el hecho de implicar a la ciudadanía como una forma de pedagogía y hacer sentir que el museo es de todos.

P. Riaño (2020) indica, siguiendo a L. Nochlin y G. Pollock, que el museo debería dejar el "ilusionismo de la materia (pincelada) para atender al materialismo (las condiciones políticas y sociales que determinan la creación de la obra de arte)" (p. 18). El mismo autor incide en la importancia de leer los símbolos que aparecen en las obras del pasado para no confundirlos con los propios de nuestro presente, pues los discursos decimonónicos de las instituciones museísticas legitiman la idea de dominación masculina. No supone esto terminar con las obras nacidas antes, sino aprovecharlas para realizar lecturas nuevas, en las que los modelos de entonces no sean referentes para los valores actuales. El autor indica que las artistas y visitantes deben poder reconocerse, pues además la ausencia de referentes femeninos en los museos trasciende también hacia los currículos escolares y las carencias que presentan. Además, se detiene en su argumentación, en la repercusión de las propias cartelas, pues en ellas se define el museo y el papel que quiere jugar: "En una cartela cabe un museo (...) una cartela es un manifiesto" (Riaño, 2020, p. 21).

A esto habría que añadir, que no solo es importante el contenido que 
presentan los instrumentos de comunicación del museo, como la cartela o sus recursos online, sino el lenguaje que utilizan para ello. Tan importante es qué se narra como la forma en que se hace.

Marián López Fernández Cao puso en marcha hace ya una década el proyecto de investigación "Estudio de los fondos museísticos desde la perspectiva de género: Museo del Prado, Museo Nacional Centro de Arte Reina Sofía, Museo Arqueológico Nacional y Museo del Traje" que ha generado la web Didáctica 2.2 Museos en Femenino. Se señalan en la web dos tipos de acciones:

la primera tiene que ver con la revisión de los sistemas de catalogación, los criterios expositivos que se aplican, los textos escritos que acompañan a los materiales expuestos, la ordenación espacial y visual de los materiales, etcétera; y la segunda con la generación de nuevas interpretaciones sobre las obras expuestas que resalten las presencias y ausencias de las mujeres o las relaciones de poder material y representativo que cada época ha desarrollado. (Museos en Femenino, Web)

En la primera acción, se señala precisamente la importancia de los textos escritos. El proyecto ha generado además tres guías didácticas orientadas a profesorado, para el Museo del Prado, el Museo Nacional Centro de Arte Reina Sofía y el Museo Nacional de Cerámica González Martí, que proponen itinerarios en los museos en los que se visibilizan a las mujeres. Las guías utilizan, por supuesto, un lenguaje inclusivo en sus textos y actividades, pero no ponen atención en analizar el lenguaje textual que emplean estos museos, sino que se centran en las claves visuales.

En este contexto, surgen varias preguntas como: ¿usan los museos un lenguaje no sexista acompañando sus narrativas?, ¿es una preocupación actual en las instituciones culturales el uso del lenguaje no sexista?

\subsection{Postura de los museos ante el uso del lenguaje inclusivo}

En el contexto de esta investigación, se ha llevado a cabo una encuesta empleando la herramienta de Google Forms, que pretendía conocer si los museos de habla hispana creen necesario el uso del lenguaje inclusivo, si creen usarlo, si cuentan con las herramientas adecuadas, etc. Para ello, se envió el cuestionario a los museos nacionales más relevantes y a los museos autonómicos de Andalucía, así como a una amplia selección de museos de la América hispanohablante. Si bien no todos los museos respondieron, la muestra es lo suficientemente amplia y los resultados presentan una 
homogeneidad suficiente como para extraer conclusiones interesantes. Los museos españoles que respondieron, a fecha 4 de julio de 2019, han sido: CAAC; Museo de Bellas Artes de Sevilla; Museo de Bellas Artes de Córdoba; Museo Arqueológico de Granada; Museo Cerralbo; Museu Nacional d’Art de Catalunya; MACBA; Agencia pública para la gestión de la Casa Natal de P.R. Picasso y otros equipamientos museísticos y culturales; $\mathrm{Mu}-$ seo del Romanticismo; Museo Arqueológico de Córdoba; Museo de Málaga; Centro Pompidou Málaga; Museo Picasso Málaga; Centro de Creación Contemporánea de Andalucía. En cuanto a museos internacionales: Museo Nacional de Bellas Artes, Chile; Museo Soumaya, México; Museos del Banco de la República, Colombia; Museo Nacional de Colombia; Museo Nacional de Arte, México; y Museo Frida Kahlo, México ${ }^{4}$.

A continuación, se presentan las preguntas y respuestas generales:

0. En primer lugar, se pedía que se identificase el museo, el cargo que ocupaba la persona que respondía el cuestionario ${ }^{5}$ el sexo de esta.

La mayoría de las personas que respondieron pertenecían a los departamentos de dirección, comunicación/relaciones públicas, conservación y gabinete pedagógico. Casi el $70 \%$ de las personas que respondieron son mujeres. Esto tiene que ver con el dato que se expuso anteriormente, de que son muchas más mujeres las que ocupan este tipo de puestos (conservación, educación, etc.). Entre las personas que respondieron que ocupan la dirección, hay una mujer (Museo de Málaga), y tres hombres (Macba, Museo Arqueológico de Granada y Museo de Bellas Artes de Córdoba).

\section{1. ¿Cree que es posible el uso del lenguaje inclusivo en el museo?}

El 91,3\% indica que sí, y el 8,7\% que no lo tiene claro, nadie responde de forma negativa. Esto indica que dentro de los museos se cree que escribir sus textos con un lenguaje no sexista no es un problema, y por supuesto denota cierta predisposición a realizarlo.

\footnotetext{
${ }^{4}$ Como se puede observar, prevalecen los museos de arte, si bien también hay museos arqueológicos y de historia. Si bien la investigación pudo ampliarse a otros museos, se quiso dar prevalencia a los del ámbito de las humanidades, por varias cuestiones. En primer lugar, por el perfil de la investigación desde la historia del arte, en segundo lugar, porque son más abundantes y visitados en muchos casos y, finalmente, porque la responsabilidad de las humanidades es aún mayor, si cabe.

${ }^{5}$ En el email donde se pedía colaboración, se requería que el cuestionario fuese enviado preferentemente a dirección o al gabinete pedagógico o de comunicación del museo.
} 
Gráfico 1.

¿Cree que es posible el uso del lenguaje inclusivo en el museo?

23 respuestas

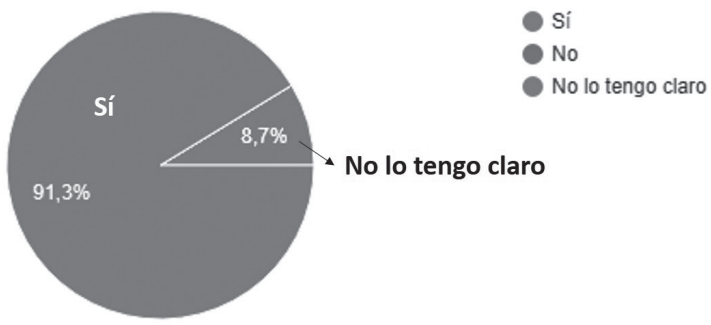

2. ¿Cree que es necesario el uso del lenguaje inclusivo en el museo?

El $82,8 \%$ cree que sí, frente al 17,4\% que no lo tiene claro, nuevamente nadie responde de forma negativa. De los cuatro museos que responden que no lo tienen claro, dos coinciden con quienes dieron la respuesta anterior, esta coincidencia es coherente, aunque también es significativo que en dos museos crean que el uso del lenguaje no sexista es posible, pero quizá no necesario, lo que sugiere una cierta predisposición, si no negativa, al menos sí reticente. Lo más revelador en cualquier caso es que un porcentaje altísimo lo cree necesario, no obstante, hay que tener en cuenta que probablemente quienes se hayan prestado a responder el cuestionario ya se hayan planteado la cuestión y tengan una predisposición a favor del tema.

Gráfico 2.

¿Cree que es necesario el uso del lenguaje inclusivo en el museo?

23 respuestas

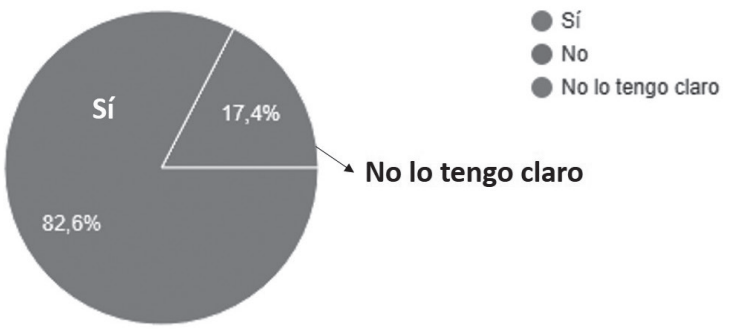


3. ¿Cuentan con una guía de estilo para redactar sus materiales y medios de difusión (web, folletos, redes sociales, cartelas, etc.) donde se incluya la necesidad de usar un lenguaje inclusivo?

Solo un 30\% cuenta con una guía. En concreto, la Casa Natal de P.R. Picasso, el Museo Cerralbo, el Museo Nacional de Bellas Artes de Chile, el Museo Arqueológico de Córdoba, el Pompidou de Málaga y el Frida Kahlo de México.

4. ¿Cree que su museo emplea un lenguaje inclusivo en sus materiales y medios de difusión?

El 8.7\% de los museos cree que nunca emplea lenguaje inclusivo, el 26\% cree que sí y el 65.2, que solo a veces.

Gráfico 3.

¿Cree que su museo emplea un lenguaje inclusivo en sus materiales y medios de difusión?

23 respuestas

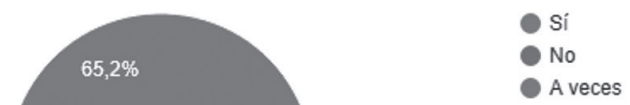

\section{A veces}

N้o

5. Cree que el uso del lenguaje inclusivo es necesario en el ámbito museístico referido a: sus artistas; personal; público; todas por igual; ninguna.

Un 95,7\% cree que es necesario en todos los ámbitos y solo un museo ha respondido que es necesario solo para el público, en concreto, el Museo Frida Kahlo. Esta respuesta es llamativa, pero puede deberse a las características de este museo, puesto que está dedicado a una única figura femenina. 
6. Parece que en el nuevo Código de Buenas Prácticas de Museos diseñado por el IAC 6 y aprobado por el MEC, se incluirá un apartado sobre la preferencia de evitar el masculino genérico ¿Están diseñando en estos momentos algún plan para implementar el uso del lenguaje inclusivo en el museo?

Solo un $13.6 \mathrm{~T} \%$ ha respondido afirmativamente, en concreto el Museo de Málaga, el Museo Nacional de Arte de México y el Museo Nacional d’Art de Catalunya. El Museo Arqueológico de Granada reconoce desconocer el Código.

\section{Añada lo que considere}

Este ha resultado un apartado de gran interés, puesto que permite conocer con mayor profundidad la opinión de los museos encuestados. Un museo dice que usan el masculino genérico siguiendo las normas de la Real Academia Española de la Lengua, aunque, si leemos a la propia Academia, en ocasiones admite que el uso del masculino genérico genera confusiones, en cuyo caso, al menos sería necesario emplear desdobles o alguna fórmula que permita especificar el sexo: "La lengua española es suficientemente rica y posee estrategias para, sin faltar en lo más mínimo a la gramática, no incurrir en los malentendidos e imprecisiones que conlleva muchas veces el uso del masculino genérico" (Guerrero Salazar, 2012b, p. 14).

También, uno de los museos explica que el uso del lenguaje no sexista es difícil por falta de espacio, esto demuestra un desconocimiento de las guías universitarias, por ejemplo, pues resulta incluso más económico. Asimismo, se hace referencia en estos comentarios a la necesidad de contar con una guía de estilo o materiales que faciliten su implementación en los museos que adolecen de estos. Por último, se hace referencia a que el uso del lenguaje no sexista depende del departamento del Museo que redacte el texto, lo que es un error manifiesto, puesto que cualquier institución debe seguir una misma línea estilística en sus publicaciones.

${ }^{6}$ El 15 de marzo de 2018 se constituyó la Comisión de Igualdad de Género en el Ámbito de la Cultura. (https://mav.org.es/se-constituye-la-comision-de-igualdad-de-genero-en-el-ambito-de-la-culturacon-la-aprobacion-de-un-plan-de-trabajo-anual/). Además, el Instituto de Arte Contemporáneo, incorporó en 2019 en el nuevo Código de Buenas Prácticas en Museos y Centros de Arte, como una prioridad, la igualdad de género y el uso del lenguaje inclusivo, evitando el uso del masculino genérico (ver M.L, 2019). 


\subsection{Revisión del uso de lenguaje inclusivo en los medios de difusión de los}

museos

La encuesta anterior se ha completado con un análisis de los instrumentos de comunicación de los museos: páginas webs, redes sociales, materiales de los museos como folletos, catálogos y guías didácticas o materiales educativos en general, no sólo de los museos que respondieron a la encuesta, sino también de alguno más por su gran relevancia. Esto se acompaña de una estadística tomada de Google Trends que permite saber la incidencia de las webs de los museos. Para realizar dicho análisis, se planteó la posibilidad de crear una herramienta de evaluación, por ejemplo, una rúbrica, pero finalmente se ha considerado hacer un análisis cualitativo y no cuantitativo, puesto que podría resultar poco objetivo. No obstante, el análisis se ha llevado a cabo siguiendo un proceso riguroso, por el cual analizar los mismos campos en todos los museos dentro de sus webs siempre que ha sido posible: apartado de directorio, de visitas, de materiales. En los casos en que ha sido posible se ha atendido también en parte a los contenidos.

Por último, otra de las cuestiones a tener en cuenta al inicio de la investigación, eran actividades realizadas en los museos en relación al uso del lenguaje no sexista, pero tan sólo se ha encontrado una celebrada en el Centro de Arte Contemporáneo de Málaga, como no, por el 8 de marzo (Web CAC).

Los museos analizados además de aquellos que respondieron al cuestionario, han sido el Museo Nacional Centro de Arte Reina Sofía, el Museo del Prado y el Museo Thyssen Bornemisza.

En general, del análisis se descubre que la mayoría de museos son más inclusivos en el uso del lenguaje en las redes sociales (Facebook e Instragam), que en las páginas webs y sobre todo que en los materiales educativos, probablemente por usar un lenguaje más directo, con predominio de la segunda persona. Uno de los errores más frecuentes aparece en el apartado de directorio, donde en vez de aparecer las secciones del museo con sus nombres genéricos (dirección, conservación, secretaría, etc.), se usa a veces el masculino, a veces el femenino y muchas veces combinados, lo que le resta unidad estilística. Otro de los fallos más frecuentes es en cuanto a las referencias a los visitantes, especialmente al público infantil, donde se suele usar la fórmula 'niños', como también sucede en los materiales educativos. En la siguiente tabla se muestran las especificidades de cada museo analizado, atendiendo a la incidencia de sus webs y redes sociales, poniendo algún error en el uso del lenguaje no sexista como ejemplo y un comentario donde se hace referencia no sólo al lenguaje sino a otros aspectos relaciona- 


\section{dos con la presencia de mujeres en los contenidos de los museos, de forma abreviada.}

Tabla 1. Fichas de los museos

\begin{tabular}{|c|c|c|c|c|c|}
\hline \multicolumn{6}{|c|}{ FICHAS DE LOS MUSEOS } \\
\hline Museos & $\begin{array}{l}\text { Titularidad/ } \\
\text { Gestión }\end{array}$ & $\begin{array}{l}\text { Incidencia } \\
\text { e internet }\end{array}$ & $\begin{array}{l}\text { Análisis web, } \\
\text { redes y materiales }\end{array}$ & $\begin{array}{l}\text { Ejemplo } \\
\text { de errores }\end{array}$ & Comentario \\
\hline \begin{tabular}{l|} 
Museo \\
Arqueológico y \\
Etnológico de \\
Granada
\end{tabular} & $\begin{array}{l}\text { Autonó- } \\
\text { mica }\end{array}$ & \begin{tabular}{|l|}
686 me gusta \\
en Facebook / \\
Web visitada en \\
Andalucía y Madrid
\end{tabular} & $\begin{array}{l}\text { Redes sociales } \\
\text { mejores que la web } \\
\text { y materiales }\end{array}$ & $\begin{array}{l}\text { "En la Sala II } \\
\text { vemos como el } \\
\text { hombre, por medio } \\
\text { de la agricultura, } \\
\text { conseguida en } \\
\text { la Revolución } \\
\text { Neolítica..." }\end{array}$ & $\begin{array}{l}\text { Utiliza algunos } \\
\text { términos de forma } \\
\text { muy correcta, pero } \\
\text { se detecta en los } \\
\text { contenidos ausencia } \\
\text { de las mujeres } \\
\text { (folleto), con visitas } \\
\text { guiadas puntuales }\end{array}$ \\
\hline $\begin{array}{l}\text { Museo de } \\
\text { Bellas Artes de } \\
\text { Córdoba }\end{array}$ & $\begin{array}{l}\text { Autonó- } \\
\text { mica }\end{array}$ & $\begin{array}{l}7887 \text { personas } \\
\text { siguen en } \\
\text { Facebook, Web } \\
\text { visitada en } \\
\text { Andalucía }\end{array}$ & $\begin{array}{l}\text { Redes sociales } \\
\text { mejores que la web } \\
\text { y materiales }\end{array}$ & $\begin{array}{l}\text { "En el fondo } \\
\text { pictórico se } \\
\text { encuentran } \\
\text { representados la } \\
\text { práctica totalidad } \\
\text { de los más notables } \\
\text { artistas" }\end{array}$ & $\begin{array}{l}\text { Escasa presencia } \\
\text { de mujeres en } \\
\text { la colección y } \\
\text { aún menos en la } \\
\text { exposición a pesar } \\
\text { de tener una sala } \\
\text { para siglo XX-XXI. }\end{array}$ \\
\hline $\begin{array}{l}\text { Museo de } \\
\text { Bellas Artes } \\
\text { de Sevilla }\end{array}$ & $\begin{array}{l}\text { Autonó- } \\
\text { mica }\end{array}$ & \begin{tabular}{|l}
20266 personas \\
siguen en Facebook. \\
Instagram $11.7 \mathrm{k}$, \\
Web visitada en \\
Andalucía y Madrid
\end{tabular} & $\begin{array}{l}\text { Redes sociales } \\
\text { mejores que la web } \\
\text { y materiales }\end{array}$ & $\begin{array}{l}\text { Biblioteca. } \\
\text { Uso limitado a } \\
\text { investigadores }\end{array}$ & $\begin{array}{l}\text { Mujeres ausentes en } \\
\text { los discursos }\end{array}$ \\
\hline $\begin{array}{l}\text { Centro } \\
\text { Andaluz de } \\
\text { Arte Contem- } \\
\text { poráneo CAAC }\end{array}$ & $\begin{array}{l}\text { Autonó- } \\
\text { mica }\end{array}$ & $\begin{array}{l}19122 \text { personas } \\
\text { siguen en Facebook, } \\
\text { Web visitada } \\
\text { en Andalucía, } \\
\text { Madrid y Valencia } \\
\text { y diversos países } \\
\text { de habla hispana e } \\
\text { inglesa }\end{array}$ & $\begin{array}{l}\text { Redes sociales } \\
\text { mejores que la web } \\
\text { y materiales }\end{array}$ & $\begin{array}{l}\text { "En este apartado } \\
\text { ofrecemos una lista } \\
\text { con una selección } \\
\text { de los autores que } \\
\text { forman parte de los } \\
\text { fondos del CAAC" }\end{array}$ & $\begin{array}{l}\text { De } 220 \text { artistas en } \\
\text { la colección, } 43 \text { son } \\
\text { mujeres }(19.5 \%)\end{array}$ \\
\hline $\begin{array}{l}\text { Agencia } \\
\text { pública para } \\
\text { la gestión } \\
\text { de la Casa } \\
\text { Natal de P R } \\
\text { Picasso y otros } \\
\text { equipamientos } \\
\text { museísticos y } \\
\text { culturales }\end{array}$ & Local & \begin{tabular}{|l|}
14455 personas \\
siguen en \\
Facebook. 1,826 \\
personas siguen \\
en Instagram, Web \\
visita en Andalucía, \\
Madrid, Italia y \\
países de habla \\
hispana
\end{tabular} & $\begin{array}{l}\text { Se detectan } \\
\text { pequeños errores } \\
\text { como: "Gracias a } \\
\text { todos por asistir". } \\
\text { (Gracias por asistir) }\end{array}$ & $\begin{array}{l}\text { "Desde esta } \\
\text { sección queremos } \\
\text { prestar ayuda al } \\
\text { investigador" }\end{array}$ & $\begin{array}{l}\text { Cuenta con guía, } \\
\text { por lo que se } \\
\text { hace un uso muy } \\
\text { adecuado. }\end{array}$ \\
\hline $\begin{array}{l}\text { Museu d'art } \\
\text { contemporani } \\
\text { de Barcelona } \\
\text { MACBA }\end{array}$ & Consorcio & \begin{tabular}{|l|}
99402 personas \\
siguen en \\
Facebook. $85.6 \mathrm{k}$ \\
personas siguen \\
en Instagram. \\
Web con gran \\
incidencia nacional \\
e internacional \\
\end{tabular} & $\begin{array}{l}\text { Redes sociales } \\
\text { mejores que la web. }\end{array}$ & $\begin{array}{l}\text { "Los visitantes } \\
\text { que tengan que } \\
\text { desplazarse en } \\
\text { silla de ruedas } \\
\text { pueden solicitar un } \\
\text { monóculo.... }\end{array}$ & $\begin{array}{l}\text { Más de } 50 \text { mujeres } \\
\text { en la colección, } \\
\text { siguen siendo } \\
\text { minoría, sobre } \\
\text { todo siendo de arte } \\
\text { contemporáneo. }\end{array}$ \\
\hline
\end{tabular}


(continuación Tabla 1)

\begin{tabular}{|c|c|c|c|c|c|}
\hline Museos & $\begin{array}{l}\text { Titularidad/ } \\
\text { Gestión }\end{array}$ & $\begin{array}{l}\text { Incidencia } \\
\text { e internet }\end{array}$ & $\begin{array}{l}\text { Análisis web, } \\
\text { redes y materiales }\end{array}$ & $\begin{array}{l}\text { Ejemplo } \\
\text { de errores }\end{array}$ & Comentario \\
\hline $\begin{array}{l}\text { Museu } \\
\text { Nacional d'Art } \\
\text { de Catalunya }\end{array}$ & Consorcio & $\begin{array}{l}85523 \text { personas } \\
\text { siguen en } \\
\text { Facebook, 26.8k } \\
\text { en Instagram, Web } \\
\text { gran incidencia } \\
\text { nacional e } \\
\text { internacional }\end{array}$ & $\begin{array}{l}\text { Redes sociales } \\
\text { mejores que la web } \\
\text { y materiales }\end{array}$ & $\begin{array}{l}\text { "Ofrecemos una } \\
\text { programación } \\
\text { especializada para } \\
\text { niños en riesgo de } \\
\text { exclusión social" }\end{array}$ & $\begin{array}{l}\text { Código ético: uno } \\
\text { de los objetivos } \\
\text { es la igualdad de } \\
\text { género. Itinerarios } \\
\text { con contenido sobre } \\
\text { mujeres. En los } \\
\text { materiales infantiles, } \\
\text { por ejemplo, sobre } \\
\text { surrealismo, no } \\
\text { hay mujeres, que } \\
\text { solo aparecen como } \\
\text { musas y hadas }\end{array}$ \\
\hline $\begin{array}{l}\text { Museo } \\
\text { Cerralbo }\end{array}$ & Estatal & $\begin{array}{l}14119 \text { personas } \\
\text { siguen en Facebook. } \\
\text { Web seguida en } \\
\text { sur, centro y este } \\
\text { peninsular }\end{array}$ & $\begin{array}{l}\text { Redes sociales } \\
\text { mejores que la web } \\
\text { y materiales. }\end{array}$ & $\begin{array}{l}\text { Atención a } \\
\text { investigadores y } \\
\text { opositores }\end{array}$ & $\begin{array}{l}\text { Mujeres levemente } \\
\text { presentes en los } \\
\text { contenidos. Bastante } \\
\text { correcto en el } \\
\text { lenguaje. }\end{array}$ \\
\hline $\begin{array}{l}\text { Museo del } \\
\text { Romanticismo }\end{array}$ & Estatal & $\begin{array}{l}17656 \text { personas } \\
\text { siguen en Facebook, } \\
\text { 13.6k en Instagram. } \\
\text { Web gran seguimiento } \\
\text { nacional y en el } \\
\text { continente americano. }\end{array}$ & $\begin{array}{l}\text { Redes sociales } \\
\text { mejores que la web } \\
\text { y materiales. }\end{array}$ & - & $\begin{array}{l}\text { Uso inclusivo del } \\
\text { lenguaje bastante } \\
\text { correcto, pero } \\
\text { sin contenidos de } \\
\text { género. }\end{array}$ \\
\hline $\begin{array}{l}\text { Centro } \\
\text { Pompidou } \\
\text { Málaga }\end{array}$ & Consorcio & $\begin{array}{l}30412 \text { personas } \\
\text { siguen en } \\
\text { Facebook, 20.9k } \\
\text { en Instagram. } \\
\text { Web seguida } \\
\text { fundamentalmente } \\
\text { en Andalucía. }\end{array}$ & $\begin{array}{l}\text { Redes sociales } \\
\text { mejores que la web }\end{array}$ & $\begin{array}{l}\text { "La entrada será } \\
\text { gratuita para } \\
\text { desempleados, } \\
\text { menores de } 18 \\
\text { años, titulares del } \\
\text { carnet joven euro, } \\
\text { docentes y alumnos } \\
\text { universitarios } \\
\text { de Bellas Artes e } \\
\text { Historia del Arte, } \\
\text { empleados de museos } \\
\text { y miembros del } \\
\text { ICOM, personas } \\
\text { discapacitadas" } \\
\end{array}$ & $\begin{array}{l}\text { La Gestión la hace } \\
\text { la Agencia pública } \\
\text { para la gestión de } \\
\text { la Casa Natal de P } \\
\text { R Picasso y otros } \\
\text { equipamientos } \\
\text { museísticos y } \\
\text { culturales, que } \\
\text { cuentan con } \\
\text { guía para uso del } \\
\text { lenguaje no sexista }\end{array}$ \\
\hline $\begin{array}{l}\text { Museo Picasso, } \\
\text { Málaga }\end{array}$ & Fundación & $\begin{array}{l}28228 \text { personas en } \\
\text { Facebook, } 49,5 \mathrm{k} \\
\text { en Instagram. Web } \\
\text { con gran incidencia } \\
\text { mundial }\end{array}$ & $\begin{array}{l}\text { Todos los textos son } \\
\text { muy adecuados. }\end{array}$ & "Desempleados" & $\begin{array}{l}\text { Es un museo que } \\
\text { presenta un alto } \\
\text { grado de inclusión } \\
\text { en todos los } \\
\text { aspectos. }\end{array}$ \\
\hline C3A, Córdoba & $\begin{array}{l}\text { Comunidad } \\
\text { Autónoma }\end{array}$ & $\begin{array}{l}3553 \text { personas } \\
\text { en Facebook, } \\
1468 \text { personas } \\
\text { en Instagram. } \\
\text { Web visitada en } \\
\text { Andalucía } \\
\end{array}$ & $\begin{array}{l}\text { Uso muy correcto } \\
\text { de lenguaje no } \\
\text { sexista }\end{array}$ & - & $\begin{array}{l}\text { Se observa además } \\
\text { una buena integración } \\
\text { de las mujeres artistas } \\
\text { en los programas } \\
\text { expositivos y de } \\
\text { residencias }\end{array}$ \\
\hline $\begin{array}{l}\text { Museo } \\
\text { Nacional de } \\
\text { Bellas Artes, } \\
\text { Chile }\end{array}$ & Estatal & $\begin{array}{l}\text { 63,3k Instagram. } \\
\text { Web gran incidencia } \\
\text { en América, España y } \\
\text { otros países europeos }\end{array}$ & Uso correcto & - & $\begin{array}{l}\text { Cuenta con una } \\
\text { guía a nivel nacional }\end{array}$ \\
\hline $\begin{array}{l}\text { Museo } \\
\text { Soumaya, } \\
\text { Ciudad de } \\
\text { México }\end{array}$ & Fundación & $\begin{array}{l}8208 \text { personas en } \\
\text { Facebook, 136k en } \\
\text { Instagram. Web } \\
\text { gran incidencia } \\
\text { mundial }\end{array}$ & $\begin{array}{l}\text { Errores en } \\
\text { apartados de } \\
\text { la web como } \\
\text { responsabilidad } \\
\text { social }\end{array}$ & $\begin{array}{l}\text { Niños, cuidadores, } \\
\text { etc. }\end{array}$ & $\begin{array}{l}\text { Se trata de un } \\
\text { Museo con un } \\
\text { gran programa de } \\
\text { integración a todos } \\
\text { los niveles }\end{array}$ \\
\hline
\end{tabular}


(continuación Tabla 1)

\begin{tabular}{|c|c|c|c|c|c|}
\hline Museos & $\begin{array}{c}\text { Titularidad/ } \\
\text { Gestión }\end{array}$ & $\begin{array}{c}\text { Incidencia } \\
\text { e internet }\end{array}$ & $\begin{array}{l}\text { Análisis web, } \\
\text { redes y materiales }\end{array}$ & $\begin{array}{c}\text { Ejemplo } \\
\text { de errores }\end{array}$ & Comentario \\
\hline $\begin{array}{l}\text { Museos del } \\
\text { Banco de la } \\
\text { República, } \\
\text { Colombia }\end{array}$ & $\begin{array}{l}\text { Banco } \\
\text { estatal }\end{array}$ & $\begin{array}{l}31158 \text { personas en } \\
\text { Facebook, 67,2k } \\
\text { Instagram. Web, } \\
\text { gran incidencia } \\
\text { mundial. }\end{array}$ & $\begin{array}{l}\text { Errores en } \\
\text { apartados de la web } \\
\text { como servicios. }\end{array}$ & $\begin{array}{l}\text { Niños, maestros, } \\
\text { etc. }\end{array}$ & $\begin{array}{l}\text { Son en realidad } \\
\text { múltiples espacios } \\
\text { museísticos }\end{array}$ \\
\hline $\begin{array}{l}\text { Museo } \\
\text { Nacional de } \\
\text { Colombia }\end{array}$ & Estatal & $\begin{array}{l}124560 \text { personas en } \\
\text { Facebook, } 37,1 \mathrm{k} \text { en } \\
\text { Instagram, Web con } \\
\text { gran incidencia en } \\
\text { América y Europa }\end{array}$ & $\begin{array}{l}\text { Errores en } \\
\text { apartados de la web } \\
\text { como visitas }\end{array}$ & $\begin{array}{l}\text { Niños, profesores, } \\
\text { compañeros, etc. }\end{array}$ & $\begin{array}{l}\text { Entre } 2015 \text { y } \\
2016 \text { hubo una } \\
\text { exposición } \\
\text { temporal sobre arte } \\
\text { y mujeres, pero } \\
\text { sería interesante } \\
\text { incorporar el } \\
\text { discurso de manera } \\
\text { permanente }\end{array}$ \\
\hline $\begin{array}{l}\text { Museo } \\
\text { Nacional de } \\
\text { Arte, México } \\
\text { D.F. }\end{array}$ & Estatal & $\begin{array}{l}536309 \text { personas } \\
\text { en Facebook, } 141 \mathrm{k} \\
\text { en Instagram. Web } \\
\text { con gran incidencia } \\
\text { mundial. }\end{array}$ & $\begin{array}{l}\text { Errores en } \\
\text { apartados de la web } \\
\text { como visitas }\end{array}$ & Maestros, etc. & $\begin{array}{l}\text { Sería interesante } \\
\text { incorporar discursos } \\
\text { con presencia de } \\
\text { las mujeres, de } \\
\text { forma visible en } \\
\text { sus medios de } \\
\text { comunicación. }\end{array}$ \\
\hline $\begin{array}{l}\text { Museo Frida } \\
\text { Kahlo, Ciudad } \\
\text { de México }\end{array}$ & - & $\begin{array}{l}\text { 173k en Instagram. } \\
\text { Web con altísima } \\
\text { incidencia mundial. }\end{array}$ & $\begin{array}{l}\text { Errores en } \\
\text { apartados de la web } \\
\text { como visitas. }\end{array}$ & Profesores, etc. & $\begin{array}{l}\text { Sería quizá importante } \\
\text { para que la artista sea } \\
\text { valorada por su propia } \\
\text { obra, no poner el } \\
\text { nombre de su esposo } \\
\text { delante del suyo } \\
\text { propio en su museo }\end{array}$ \\
\hline $\begin{array}{l}\text { Museo del } \\
\text { Prado }\end{array}$ & Estatal & \begin{tabular}{|l|}
990409 personas \\
en Facebook, 503k \\
Instagram. Web \\
con grandísima \\
incidencia mundial. \\
52662 personas en \\
canal de Youtube
\end{tabular} & $\begin{array}{l}\text { Redes sociales } \\
\text { mejores que la web, } \\
\text { aunque es bastante } \\
\text { correcto. }\end{array}$ & Profesores, etc. & $\begin{array}{l}\text { Si bien ha empezado } \\
\text { tarde en la } \\
\text { incorporación de } \\
\text { mujeres artistas en } \\
\text { las salas y en sus } \\
\text { discursos, empiezan } \\
\text { a incluirse }\end{array}$ \\
\hline MNCARS & Estatal & \begin{tabular}{|l|}
383083 personas \\
en Facebook, $158 \mathrm{k}$ \\
Instagram. Web \\
con grandísima \\
incidencia mundial
\end{tabular} & $\begin{array}{l}\text { Uso bastante } \\
\text { adecuado }\end{array}$ & $\begin{array}{l}\text { Uso de textos muy } \\
\text { asépticos }\end{array}$ & $\begin{array}{l}\text { Sería necesaria } \\
\text { mayor presencia } \\
\text { de mujeres artistas, } \\
\text { especialmente entre } \\
\text { artistas actuales en } \\
\text { sus exposiciones } \\
\text { temporales, } \\
\text { aunque promueve } \\
\text { la integración, por } \\
\text { ejemplo, mediante } \\
\text { el LGTBIQ+, el } \\
\text { problema es relacionar } \\
\text { estas acciones sólo con } \\
\text { efemérides destacadas. } \\
\text { Cuenta siempre } \\
\text { con un itinerario de } \\
\text { mujeres, que incluye } \\
\text { obras de Maruja } \\
\text { Mallo, Remedios } \\
\text { Varo, etc. }\end{array}$ \\
\hline $\begin{array}{l}\text { Museo Thyssen } \\
\text { Bornemisza }\end{array}$ & $\begin{array}{l}\text { Fundación } \\
\text { Pública }\end{array}$ & \begin{tabular}{|l|}
263107 personas \\
en Facebook, 191k \\
Instagram. Web \\
con grandísima \\
incidencia mundial.
\end{tabular} & $\begin{array}{l}\text { Errores en } \\
\text { apartados de la web } \\
\text { como Visitas. }\end{array}$ & $\begin{array}{l}\text { “Solo o en grupo?” } \\
\text { "Visita con tu } \\
\text { profesor" }\end{array}$ & $\begin{array}{l}\text { Mujeres incluidas } \\
\text { en los discursos y } \\
\text { visitas temáticas. }\end{array}$ \\
\hline
\end{tabular}




\section{RECOMENDACIONES}

En cuanto a las recomendaciones particulares, lo cierto es que se trata de un trabajo que debieran hacer lingüistas con experiencia en el tema, aunque se debe señalar que existen algunas cuestiones fáciles de solventar, pues si bien los museos españoles y de la mayoría de los países adolecen de una guía común, e incluso de materiales propios, lo cierto es que dentro de las guías universitarias y otras como la de Fundéu, podrían encontrar respuesta a la mayoría de las dudas que pudieran plantearse, pues como indica Bejarano Franco (2013), "La propia lengua posee numerosos recursos antisexistas que están a nuestra disposición para evitar incurrir en el sexismo lingüístico. Incorporar estos recursos o fórmulas implica cambiar hábitos adquiridos desde la edad temprana que además han sido enseñados en la escuela" (p. 86).

No obstante, sería preciso trabajar en un documento común y en formación específica para el personal de los museos. En tal sentido, la guía chilena podría ser una buena aliada en esta tarea ${ }^{7}$. Atendiendo a esta guía, y a la guía Fundéu (Web), a la Guía de las Naciones Unidas (Web), y a la Guía para un uso igualitario y no sexista del lenguaje y de la imagen en la Universidad de Jaén (Guerrero Salazar, 2012b) ${ }^{8}$, se podrían realizar las sugerencias que se presentan en la Tabla 2, según los errores más comunes percibidos en el análisis, donde se presentan, además, una posible solución junto con un ejemplo, y qué documento aporta dicha solución?.

\footnotetext{
${ }^{7}$ Es el único caso en el que existe una guía sobre uso de lenguaje no sexista para todos los museos del país. Este documento parte de otra guía anterior, realizada por el propio Ministerio de Cultura. Esto es muy positivo, puesto que habrá una homogeneidad que facilita la educación y aceptación, en este caso, del lenguaje no sexista. Realizada en el año 2012, es un documento que se centra más en los conceptos, en datos y en fomentar la investigación y fórmulas para ser más equitativos, que en dar recomendaciones lingüísticas en sí, puesto que esto lo encontramos en la guía del Consejo Nacional de Cultura y de las Artes (2016).

${ }^{8} \mathrm{Se}$ ha elegido esta guía en concreto, no solo por ser la usada en la institución a la que pertenezco, sino por ser la primera que incluye también el uso de la imagen y por ser su autora una de las mayores expertas en este tema de nuestro país, autora de numerosas guías, algunas de las cuales son de las pocas que han sido valoradas positivamente por la RAE.

${ }^{9}$ Las recomendaciones se hacen siguiendo las guías nombradas previamente y soluciones adoptadas por otros museos a los mismos casos.
} 
Tabla 2. Recomendaciones a los problemas más frecuentes

\begin{tabular}{|c|c|c|c|}
\hline \multicolumn{4}{|c|}{ RECOMENDACIONES A LOS PROBLEMAS MÁS FRECUENTES } \\
\hline Problema & Posible solución & $\begin{array}{c}\text { Museo o guía que ya lo } \\
\text { usa o recomienda }\end{array}$ & Ejemplo \\
\hline $\begin{array}{l}\text { Director, } \\
\text { secretaria, etc. }\end{array}$ & Dirección, secretaría, etc. & Guía de Chile, p. 7 & $\begin{array}{l}\text { La dirección del museo } \\
\text { le invita a... }\end{array}$ \\
\hline Niño/s & $\begin{array}{l}\text { Público infantil; visitantes } \\
\text { con edades entre X y X }\end{array}$ & Casa natal Picasso & $\begin{array}{l}\text { Entrada gratuita para } \\
\text { público infantil }\end{array}$ \\
\hline $\begin{array}{l}\text { Padres con } \\
\text { niños }\end{array}$ & Familias & Propuesta propia & $\begin{array}{l}\text { Visitas temáticas para } \\
\text { familias }\end{array}$ \\
\hline Profesor/es & $\begin{array}{l}\text { Profesorado; personal } \\
\text { docente }\end{array}$ & $\begin{array}{l}\text { Guía UJA (Guerrero, } \\
\text { p. 11), Museo del } \\
\text { Romanticismo }\end{array}$ & $\begin{array}{l}\text { Entrada gratuita para el } \\
\text { profesorado }\end{array}$ \\
\hline Alumno/s & $\begin{array}{l}\text { Alumnado/estudiantes, } \\
\text { escolares }\end{array}$ & $\begin{array}{l}\text { Guía UJA (Guerrero, } \\
\text { p. 11); Museo } \\
\text { Arqueológico de } \\
\text { Granada }\end{array}$ & $\begin{array}{l}\text { Entrada gratuita para } \\
\text { escolares }\end{array}$ \\
\hline $\begin{array}{l}\text { El/los artista/s; } \\
\text { creador/es; } \\
\text { autor/es }\end{array}$ & $\begin{array}{l}\text { Eliminar artículo o } \\
\text { desdoblar; introducir } \\
\text { delante 'personas'; } \\
\text { profesionales de las artes }\end{array}$ & Guía de Chile, pp. 4, 5 & $\begin{array}{l}\text { A la inauguración } \\
\text { acudirán profesionales } \\
\text { de las artes }\end{array}$ \\
\hline $\begin{array}{l}\text { Gestores } \\
\text { culturales, } \\
\text { críticos de arte, } \\
\text { etc. } \\
\end{array}$ & $\begin{array}{l}\text { Profesionales de la } \\
\text { gestión cultural, crítica } \\
\text { de arte, etc.; introducir } \\
\text { delante 'personas' }\end{array}$ & Guía de Chile, p. 5 & $\begin{array}{l}\text { A la inauguración } \\
\text { acudirán profesionales } \\
\text { de la gestión cultural }\end{array}$ \\
\hline $\begin{array}{l}\text { Usuarios, } \\
\text { voluntarios, } \\
\text { socios }\end{array}$ & $\begin{array}{l}\text { Visitantes; Voluntariado; } \\
\text { socios y socias }\end{array}$ & $\begin{array}{l}\text { Museo Cerralbo; Guía } \\
\text { UJA (Guerrero, pp. } \\
14,17 \text { ) }\end{array}$ & $\begin{array}{l}\text { Disponibles audioguías } \\
\text { para visitantes con } \\
\text { problemas auditivos }\end{array}$ \\
\hline $\begin{array}{l}\text { Asociación } \\
\text { de amigos del } \\
\text { museo }\end{array}$ & $\begin{array}{l}\text { Asociación de amigas y } \\
\text { amigos del museo }\end{array}$ & Propuesta propia & - \\
\hline $\begin{array}{l}\text { Investigadores, } \\
\text { opositores }\end{array}$ & $\begin{array}{l}\text { Personal investigador, } \\
\text { opositor/ investigación }\end{array}$ & Propuesta propia & $\begin{array}{l}\text { El archivo será de } \\
\text { acceso restringido para } \\
\text { investigación }\end{array}$ \\
\hline Candidato/s & Candidatura o desdoblar & (Guerrero, p. 15) & $\begin{array}{l}\text { Puede presentar su } \\
\text { candidatura... }\end{array}$ \\
\hline Ciudadanos & $\begin{array}{l}\text { Ciudadanía, personas } \\
\text { con nacionalidades, } \\
\text { miembros... }\end{array}$ & Propuesta propia & $\begin{array}{l}\text { Gratuito para personas } \\
\text { con nacionalidad } \\
\text { europea }\end{array}$ \\
\hline $\begin{array}{l}\text { Eliminar } \\
\text { artículos y } \\
\text { determinantes } \\
\text { (el, aquellos, los, } \\
\text { uno) }\end{array}$ & $\begin{array}{l}\text { Quien/es, cada, alguien, } \\
\text { etc. }\end{array}$ & Guía de Chile, p. 6 & $\begin{array}{l}\text { Quienes acudan al } \\
\text { museo... }\end{array}$ \\
\hline $\begin{array}{l}\text { Adverbios de } \\
\text { cantidad (pocos, } \\
\text { muchos) }\end{array}$ & Minoría, mayoría & Guía de Chile, p. 6 & La mayoría de artistas... \\
\hline $\begin{array}{l}\text { El hombre (para } \\
\text { referirnos a la } \\
\text { humanidad) }\end{array}$ & $\begin{array}{l}\text { Humanidad, población, } \\
\text { personajes, ser humano, } \\
\text { etc. }\end{array}$ & Guía de Chile, p. 6 & $\begin{array}{l}\text { La evolución del ser } \\
\text { humano... }\end{array}$ \\
\hline
\end{tabular}




\section{CONCLUSIONES}

Es un hecho que nuestros museos adolecen aún de propuestas discursivas que incluyan todas las realidades culturales y de género, tanto en sus colecciones como en sus políticas de adquisición y en sus contenidos, relegándose generalmente las propuestas relacionadas con las mujeres a las actividades por la conmemoración del Día de la Mujer. En este contexto, el uso del lenguaje no sexista apenas ha sido implementado, no obstante, además de que posiblemente pronto sea una obligación, dada la redacción del nuevo código de buenas prácticas por el IAC, por lo que se desprende de los cuestionarios aplicados, los museos están dispuestos a intentarlo y lo creen necesario y posible. Es por ello que tenemos el reto de implementar recursos que permitan una integración del lenguaje no sexista en nuestros museos como una forma de integrar no solo a todas las personas, sino de contribuir a un desarrollo social más equitativo, que es uno de los fines de los museos, según su definición. Para ello será necesario realizar, además, estudios multidisciplinares desde las propias instituciones museísticas y las universidades, en las que se cuente con profesionales de la historia del arte, antropología y, por supuesto, lingüística, pues esto, en definitiva, para el museo sería una cuestión de posicionamiento a favor de todas las posibles realidades culturales, tal y como señala García Sampedro (2018):

El traslado al museo de todas estas circunstancias identitarias relativas a la mujer supondría considerar que dicho lugar es capaz de ofrecerse como un territorio dialéctico comprometido. Por tanto, supondría un espacio que se posiciona críticamente para contener todas las posibles interpretaciones de la realidad cultural y todas las posibles subjetividades que conviven en este mundo, desde lo racial hasta lo afectivo. (p. 51)

\section{REFERENCIAS}

Acevedo Huerta, E. J. (2010). La transmisión del androcentrismo en los procesos de enseñanza-aprendizaje formales (II). Temas para la educación. Revista digital para profesionales de la enseñanza 8, 1-9. Disponible en: https:// www.feandalucia.ccoo.es/docu/p5sd7196.pdf.

Bejarano Franco, M.T. (2013). El uso del lenguaje no sexista como herramienta para construir un mundo más igualitario. Revista de Comunicación Vivat Academia 124, pp.79-89.

Breda, P. (1999). Recomendaciones para un uso no sexista del lenguaje. Cultura y Deporte. Museos +Sociales. https://www.culturaydeporte.gob.es/museosmassociales/presentacion.html 
Butler, J. (1990). El género en disputa. Madrid: Paidós.

Diccionario de la Real Academia Española de la Lengua. Disponible en: https:// dle.rae.es/?id=LFNhnwF.

EFE. (2018). Tenerife busca nombre "no sexista" para el Museo de la Naturaleza y el Hombre. El Periódico [23 de abril de 2018], s.p. Disponible en: https://www.elperiodico.com/es/ocio-y-cultura/20180423/tenerife-buscanombre-no-sexista-para-el-museo-de-la-naturaleza-y-el-hombre-6778176

Expósito Molina, C. (2012). ¿Qué es eso de la interseccionalidad? Aproximación al tratamiento de la diversidad desde la perspectiva de género en España. Investigaciones feministas 3, 203-222.

Fernández Paradas, A.R. (2017). Patrimonios invisibles. Líneas de investigación desde la perspectiva de género y la recuperación de la memoria LGTB. Vivat Academia. Revista de Comunicación 141, 115-137.

Fernández Valencia, A. (2012). La historia de las mujeres en los museos: discursos, realidades y protagonismos. El protagonismo de las mujeres en los museos (pp. 11-30). Madrid: Fundamentos.

Fundéu. Lenguaje Inclusivo. https://www.fundeu.es/lenguaje-inclusivo/. (Consultado el 25 de junio de 2019).

García, Á. (2016). El techo de cristal de las mujeres en los museos españoles. El País [14 de junio de 2016), s.p. Disponible en: https://elpais.com/cultura/2016/06/13/actualidad/1465830534_846045.html

García Ranedo, M. (2018). Desempeños de género, sexo y raza en el museo. Dossiers feministes 23, 43-61.

García-Sampedro, M. y Gutiérrez Berciano, S. (2018). El museo como espacio multicultural y de aprendizaje: algunas experiencias inclusivas. Liño. Revista Anual de Historia del Arte 24, 117-128.

Guerrero Salazar, S. (2012a). Las guías de uso no sexista del lenguaje editadas en castellano por las universidades españolas (2008-2012). Historia(s) de mujeres en homenaje a María Teresa López Beltrán (pp. 118-132), vol. 1. Málaga: Perséfone.

Guerrero Salazar, S. (2012b). Guía para un uso igualitario y no sexista del lenguaje y de la imagen en la Universidad de Jaén. Jaén: Universidad de Jaén.

Hernández Hernández, F. (2010). Museos, multiculturalidad e inclusión social. II Seminario de Investigación en Museología de los Países de Lengua Portuguesa y Española (pp. 407-417). Buenos Aires: ICOM. Disponible en: https://ler.letras.up.pt/uploads/ficheiros/10370.pdf

ICOM (2017). https://icom.museum/es/news/the-challenge-of-revising-themuseum-definition/ (Consultado el 17 de junio de 2019).

Informe MAV. Disponible en: https://mav.org.es/informe-mav-18-presenciade-mujeres-artistas-en-arco-madrid-art-madrid-hybrid-y-justmad-2018/ (Consultado el 17 de junio de 2019).

RAE (2020). Informa sobre el uso del lenguaje no sexista de la Real Academia Española de la Lengua. https://www.rae.es/sites/default/files/Informe_lenguaje_inclusivo.pdf (Consultado el 1 de junio de 2020). 
Lakoff, R. (1973). Language and Woman's Place. Language in Society 2(1), 45-80. Lavado, P.J. (2011). Museos para todos. Accesibles, inclusivos y multiculturales. ICOM CE Digital 2, 8-19.

Ley Orgánica 3/2007, de 22 de marzo, para la igualdad efectiva de mujeres y hombres. Disponible en: https://www.boe.es/buscar/act.php?id=BOEA-2007-6115 (Consultado el 25 de junio de 2019).

Llorent-Bedmar, V., Cobano-Delgado Palma, V. (2014). La mujer en los libros de texto de bachillerato en España, Cadernos de Pesquisa 444(151), 156175.

Mantas Fernández, R. y Luque Rodrigo, L. (2010). Las mujeres en el espacio pintado: de la Edad Moderna a la Contemporánea. Asparkía: investigación feminista 21, 47-64.

Mayayo, P. (2011). Historias de mujeres, historias del arte. Madrid: Cátedra.

Ministerio de Educación, Cultura y Deporte (2016). Estadística de museos y colecciones museográficas. Disponible en: https://www.culturaydeporte. gob.es/dam/jcr:59ee8187-e757-4bb1-a332-5119e48ccc11/Museos_y_Colecciones_Museograficas_2016.pdf

M.L. (2019). Igualdad de género y lenguaje inclusivo, también en los museos. La voz de Galicia [8 de febrero de 2019], s.p. Disponible en: https://www. lavozdegalicia.es/noticia/cultura/2019/02/07/igualdad-genero-lenguajeinclusivo-museos/00031549565868978320529.htm

Moral Ruiz, C. y Mantas Fernández, R. (2019). Análisis de cuestiones de género en las asignaturas de humanidades de educación secundaria en Andalucía, Avances en Ciencias de la Educación y del Desarrollo, 2018 (pp. 446-451). Granada: Universidad de Granada.

Mujeres en las Artes Visuales. https://mav.org.es/ (Consultado el 24 de junio de 2019). / https://mav.org.es/se-constituye-la-comision-de-igualdad-degenero-en-el-ambito-de-la-cultura-con-la-aprobacion-de-un-plan-de-trabajo-anual/ (Consultado el 25 de junio de 2019).

Museo Nacional de Mujeres artistas. https://nmwa.org/ (Consultado el 24 de junio de 2019).

Museos en Femenino. https://museosenfemenino.es/ (Consultado el 1 de junio de 2020).

Obra Comentada del Museo del Prado. Magdalena Ventura y su marido (La Mujer Barbuda). Disponible en: https://www.youtube.com/watch?v=wtsW7A-yME (Consultado el 25 de junio de 2019).

Quirosa García, V. y Amaro Martos, I. (2019). Educación y género en los museos nacionales: proyectos y experiencias. Avances en Ciencias de la Educación y del Desarrollo, 2018 (452-457). Granada: Universidad de Granada.

Reilly, M. (11 de julio de 2017). What Is Curatorial Activism?, Artnews, s.p. Disponible en: http://www.artnews.com/2017/11/07/what-is-curatorialactivism/ (Consultado el 17 de junio de 2019).

Riaño, P. H. (2020). Las invisibles ¿Por qué el Museo del Prado ignora a las mujeres? Madrid: Capitán Swing. 
Rubio, A. (2016). El lenguaje y la igualdad efectiva de mujeres y hombres. Revista de Bioética y Derecho Perspectivas Bioéticas 38, 5-24.

Spindler, G. D. (1993). La transmisión de la cultura. Lecturas de antropología para educadores (pp. 205-242). Madrid: Trotta.

UNESCO. Disponible en: https://unesdoc.unesco.org/ark:/48223/pf0000054 668).

UNESCO. Disponible en: https://unesdoc.unesco.org/ark:/48223/pf0000114 950 (Consultado el 17 de junio de 2019).

VVAA. (2012). Guía para la incorporación del enfoque de género en museos. Santiago: Dirección de Bibliotecas, Archivos y Museos.

VVAA. (2013). Museos, género y sexualidad. ICOM Digital España 8. Disponible en: https://issuu.com/icom-ce_librovirtual/docs/icom-ce_digital_08 (Consultado el 25 de junio de 2019).

VVAA. (2016). Guía de lenguaje inclusivo de género. Chile: Consejo Nacional de la Cultura y las Artes.

Web CAC Málaga. http://cacmalaga.eu/2018/02/27/lenguaje-inclusivo/ (Consultado el 25 de junio de 2019).

Web Mar García Ranedo. Disponible en: http://www.margarciaranedo.com/ decoy.html (Consultado el 25 de junio de 2019).

Web Museo Nacional Centro de Arte Reina Sofía. Disponible en: https://www. museoreinasofia.es/educacion/recursos-educativos/itinerarios-adultos (Consultado el 25 de junio de 2019).

Web Museo de la Naturaleza y la Arqueología de Tenerife. https://www.webtenerife.com/que-visitar/museos/museo+de+la+naturaleza+y+el+hombre. htm (Consultado el 25 de junio de 2019).

Web Museos en Femenino. http://www.museosenfemenino.es/proyecto (Consultado el 25 de junio de 2019).

Web ONU. Lenguaje inclusivo. https://www.un.org/es/gender-inclusive-language/guidelines.shtml (Consultado el 25 de junio de 2019).

Web Verónica Ruth Frías. Disponible en: http://cargocollective.com/veronicaruthfrias/ART-NOW (Consultado el 25 de junio de 2019).

Web Yolanda Domínguez. Disponible en: https://yolandadominguez.com/ portfolio/estamos-aqui/ (Consultado el 25 de junio de 2019). 